\title{
Interaction between DNMT3B and MYH11 via hypermethylation regulates gastric cancer progression
}

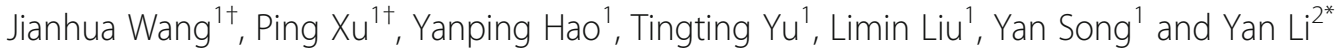

\begin{abstract}
Background: Gastric cancer (GC) has an unwelcoming prognosis when diagnosed at an advanced stage. The purpose of this study was to examine the expression of myosin heavy chain 11 (MYH11) in GC and mechanisms related.

Methods: The MYH11 expression in GC was investigated via the SangerBox platform. MYH11 expression in GC tissues and cell lines was examined by immunohistochemistry, RT-qPCR, and western blot. The relationship between MYH11 expression and patients' prognosis was analyzed. The effects of MYH11 on the biological behaviors of GC cells were investigated by gain-of-function experiments. Bioinformatics analysis was used to find genes with relevance to MYH11 expression in GC. The relationship was verified by luciferase and ChIP-qPCR assays, followed by rescue assay validation. The causes of MYH11 downregulation in GC were verified by quantitative methylation-specific PCR. Finally, the effect of MYH11 on tumor growth was examined.

Results: MYH11 was downregulated in GC and predicted poor prognoses. MYH11 reverted the malignant phenotype of GC cells. MYH11 repressed the TNFRSF14 expression by binding to the TNFRSF14 promoter. TNFRSF14 reversed the inhibitory effect of MYH11 on the malignant phenotype of GC cells. The methylation of the MYH11 promoter was elevated in GC, which was correlated with the elevated DNMT3B in GC. Overexpression of DNMT3B repressed transcription of MYH11 by promoting its methylation. Also, MYH11 upregulation inhibited tumor growth.
\end{abstract}

Conclusion: DNMT3B inhibits MYH11 expression by promoting its DNA methylation, thereby attenuating the repressive effect of MYH11 on the transcriptional of TNFRSF14 and promoting the progression of GC.

Keywords: MYH11, TNFRSF14, DNMT3B, Gastric cancer, Methylation

\section{Background}

Gastric cancer (GC) is expected to affect 26,560 people and cause 11,180 deaths in the United States in 2021 [1]. Even though it is no longer the most frequent malignancy, GC remains the third leading cause of cancerrelated death worldwide and the most frequent cancer in

\footnotetext{
*Correspondence: liyan_1281@163.com

†Jianhua Wang and Ping Xu contributed equally to this work.

${ }^{2}$ Department of Obstetrics and Gynecology, The Yancheng Clinical College of Xuzhou Medical University, The First People's Hospital of Yancheng, No. 66, Renmin South Road, Yancheng 224001, Jiangsu, People's Republic of China

Full list of author information is available at the end of the article
}

the Eastern Asia [2]. The most majority (about 90\%) of $\mathrm{GC}$ are adenocarcinomas, which stem from the glands of the most superficial layer, or the mucosa, of the stomach [3]. Most of the diagnoses made in the Western world are at late stages during which time the treatment is largely ineffective [4]. Chemotherapy is the regular firstline treatment option for patients with advanced GC and a good performance status, and chemoresistance remains the main challenge in the treatment of GC patients [5]. Therefore, there has been a strong drive to explore molecular mechanisms underlying GC progression to develop new therapies for GC.

(c) The Author(s). 2021 Open Access This article is licensed under a Creative Commons Attribution 4.0 International License, which permits use, sharing, adaptation, distribution and reproduction in any medium or format, as long as you give appropriate credit to the original author(s) and the source, provide a link to the Creative Commons licence, and indicate if changes were made. The images or other third party material in this article are included in the article's Creative Commons licence, unless indicated otherwise in a credit line to the material. If material is not included in the article's Creative Commons licence and your intended use is not permitted by statutory regulation or exceeds the permitted use, you will need to obtain permission directly from the copyright holder. To view a copy of this licence, visit http://creativecommons.org/licenses/by/4.0/ The Creative Commons Public Domain Dedication waiver (http://creativecommons.org/publicdomain/zero/1.0/) applies to the data made available in this article, unless otherwise stated in a credit line to the data. 
Myosin heavy chain 11 (MYH11), encoded by the MYH11 gene, is a smooth muscle myosin of the myosin heavy chain family [6]. It locates on 16P13.11, in 5-10\% of de novo acute myeloid leukemia with an inv.(16)(p13q22) or $\mathrm{t}(16 ; 16)$ (p13;q22) that formed a fusion gene between CBFB/MYH11 [7]. Mutations of the MYH11 gene have been reported in various forms of cancers, including head and neck cancer [8], non-smallcell lung cancer [9], bladder cancer [10], colon adenocarcinoma [11] as well as GC [12]. However, little is known about its specific role in GC, which awaits to be explored. Moreover, a protein-protein interaction network in a recent work identified MYH11 as a differentially expressed transcription factors in colorectal cancer to be related with metabolism-related genes [13]. Thus, we wondered if the possible role of MYH11 in GC was dependent on its transcription factor role. Furthermore, DNA methylation has a vital part in tumorigenesis through modulating the activation of oncogenes and the depletion of tumor suppressors, while the DNA methylation of MYH11 promoter was revealed to be engaged in the progression of GC [14]. This study, as a consequence, investigated the expression of MYH11 in GC and analyzed the association of MYH11 expression with the DNA methylation in GC. In addition, the possible role of MYH11 in GC was further investigated in vitro and in vivo. Moreover, we also set to determine the downstream target of MYH11 in GC. The answer to these questions might offer a novel strategy for GC diagnostic strategy and treatment.

\section{Methods}

\section{Patients}

GC tumor tissues and their adjacent tissues were collected from 40 patients who underwent surgery at the First People's Hospital of Yancheng between February 2014 and January 2015. All patients had a complete medical history, did not have other malignancies, and did not receive preoperative radiotherapy or chemotherapy. The tissues were stored at $-80^{\circ} \mathrm{C}$ immediately after surgery. The study protocol was approved by the Ethics Committee of the First People's Hospital of Yancheng. Written informed consent was acquired from all of the patients.

\section{Immunohistochemistry (IHC)}

The tissues were fixed using $10 \%$ formalin, then embedded in paraffin and cut into $4-\mu \mathrm{m}$ sections. Xylene and alcohol were used for dewaxing and rehydration. Endogenous peroxidase activity was blocked by using hydrogen peroxide $(30 \%)$, and the sections were boiled for approximately $3 \mathrm{~min}$ with citrate buffer $(\mathrm{pH}=6.0)$. Next, normal goat serum was used to incubate the sections to reduce non-specific binding. The tissue sections were incubated $\left(4{ }^{\circ} \mathrm{C}, 12 \mathrm{~h}\right)$ with primary antibodies to MYH11 (1:250, ab133567, Abcam, Cambridge, UK), TNFRSF14 (1:250, \#PA5-20237, Thermo Fisher Scientific Inc., Waltham, MA, USA), and Ki67 (1:200, ab16667, Abcam) and with secondary antibody to IgG (1:1000, ab6721, Abcam) for $2 \mathrm{~h}$ at ambient temperature. Finally, the sections were stained with 3,3-diaminobenzidine for $60 \mathrm{~s}$, stained with hematoxylin for $2 \mathrm{~min}$, and sealed with neutral resin. A fluorescence photomicroscope was used to acquire images (Nikon Instruments Inc., Melville, NY, USA), and the positivity rate was measured by Image J software.

The expression was assessed based on staining intensity and percentage of positive cells by two pathologists who were unaware of the grouping. The intensity of staining was scored as 0 (negative), 1 (weakly negative), 2 (weakly positive), and 3 (strongly positive). The percentage scores of positive cells in each single field of view were $1(0-25 \%), 2(26-50 \%), 3(51-75 \%)$, and 4 (76-100\%). We multiplied the above two scores together to give a final score of 0 to 12 .

\section{RNA extraction and RT-qPCR}

Total RNA was isolated from tissues and cells with the help of TRIzol reagent (Takara Holdings Inc., Kyoto, Japan). The concentration and purity of RNA samples were measured by Nanodrop 2000 (Thermo Fisher Scientific). Total RNA was reversely transcribed to cDNA using the PrimeScript RT kit (Takara). Then, RT-qPCR was performed using TB Green Premix Ex Taq II (Takara) and ABI Prism 7500 Sequence Detection System (Applied Biosystems, Inc., Foster City, CA, USA). Glyceraldehyde-3-phosphate dehydrogenase (GAPDH) was selected as a housekeeping gene, and the comparative cycle threshold $(\mathrm{Ct})$ method $\left(2^{-\Delta \Delta \mathrm{Ct}}\right)$ was used to analyze differences in each transcript. The primer sequences for the tested genes are provided in Table 1.

\section{Cell culture and treatment}

GES-1 (CL-0563) and GC cell line MKN-7 (CL-0574) were purchased from Procell (Wuhan, Hubei, China). GC cells AGS (CRL-1739), SNU-16 (CRL-5974), NCI-N87 (CRL-5822) were from ATCC (Manassas, VA, USA). All cells were cultivated at $37^{\circ} \mathrm{C}$ in Roswell Park Memorial Institute-1640 complete medium (PM150110B, Procell) plus $10 \%$ FBS with $1 \%$ penicillin/streptomycin at $5 \% \mathrm{CO}_{2}$.

The overexpressed (oe) DNA plasmids oe-MYH11, oeTNFRSF14, oe-DNMT3B and control oe-negative control (NC) used for cell transfection were from VectorBuilder (Guangzhou, Guangdong, China). Lipofectamine 2000 (Thermo Fisher) was used for all transfections. Dimethylsulfoxide (DMSO) and DNA methylation inhibitor 5-aZa-CDR (CAS No. 2353-33-5) were purchased from Sigma-Aldrich Chemical Company (St Louis, MO, 
Table 1 Primer used for RT-qPCR

\begin{tabular}{lll}
\hline Gene & Forward primer $\mathbf{( 5}^{\prime} \mathbf{- 3} \mathbf{)}$ & Reverse primer $\mathbf{( 5}^{\prime} \mathbf{- 3} \mathbf{)}$ \\
\hline MYH11 & GTCCAGGAGATGAGGCAGAAAC & GTCTGCGTTCTCTTTCTCCAGC \\
TNFRSF14 & TTCTCTCAGGGAGCCTCGTCAT & CTCACCTTCTGCCTCCTGTCTT \\
DNMT3B & TAACAACGGCAAAGACCGAGGG & TCCTGCCACAAGACAAACAGCC \\
GAPDH & GTCTCCTCTGACTTCAACAGCG & ACCACCCTGTTGCTGTAGCCAA \\
\hline
\end{tabular}

Note: MYH11, myosin heavy chain 11; TNFRSF14/HVEM, herpes virus entry mediator; DNMT3B, DNA methyltransferase 3b; GAPDH,

glyceraldehyde-3-phosphate dehydrogenase

USA). The GC cells were treated with 5-aZa-CDR dissolved in DMSO at $5 \mu \mathrm{M}$ for $24 \mathrm{~h}$ for DNA demethylation [15].

\section{Western blot}

The cells were lysed using radio immunoprecipitation assay lysis buffer on ice (Beyotime, Shanghai, China). Proteins were quantified by bicinchoninic acid assay kit analysis (Thermo Fisher), separated by $10 \%$ sodium dodecyl sulfate-polyacrylamide gel electrophoresis, and transferred to polyvinylidene difluoride membranes (Millipore Corp, Billerica, MA, USA). The membranes were sealed using $5 \%$ skim milk powder and then incubated overnight at $4{ }^{\circ} \mathrm{C}$ with the primary antibody and with the secondary antibody for $2 \mathrm{~h}$ at ambient temperature. Finally, the protein bands were visualized by the Enhanced Chemiluminescent Western Blotting Substrate Kit (Abcam). Relative expression of proteins was analyzed using Quantity One software with GAPDH as an internal reference. All antibodies used in the present study is exhibited in Table 2.

\section{Quantitative methylation-specific PCR (qMSP)}

Human genomic DNA was obtained from the tissues or cells using a genomic DNA kit (TIANGEN Biotech, Beijing, China) and then modified with bisulfite using a DNA methylation kit (Zymo Research, Orange, CA, USA). PCR products were evaluated by using $\mathrm{qPCR}$. The MSP primers for the MYH11 promoter CpG island were designed using MethPrimer (http://www.urogene.org/cgi-bin/methprimer/ methprimer.cgi) with the following primer sequences: left methylated-specific primer: CGGGGAGTAGGAAGGTTA TTC; right methylated-specific primer: ACAACCCAAA

Table 2 Antibodies used for western blot

\begin{tabular}{ccll}
\hline Antibodies & Dilution & Catalog number & Manufacturers \\
\hline \multicolumn{2}{l}{ Primary antibodies } & & \\
MYH11 & $1 / 1000$ & ab133567 & Abcam \\
TNFRSF14 & $1 / 500$ & \#PA5-20237 & Thermo Fisher Scientific \\
GAPDH & $1 / 1000$ & $\# 2118$ & Cell signaling technology \\
Secondary antibody & & \\
IgG & $1 / 2000$ & ab6721 & Abcam \\
\hline
\end{tabular}

Note: MYH11, myosin heavy chain 11; GAPDH, glyceraldehyde-3-phosphate dehydrogenase; MYH11, myosin heavy chain 11
AAAAACAAACG. left unmethylated-specific primer: GTTGGGGAGTAGGAAGGTTATTT; right unmethylated-specific primer: AACAACCCAAAAAAAA CAAACAC.

\section{Cell counting kit-8 (CCK-8)}

Changes in the proliferative capacity of cells were detected using a CCK-8 kit (Dojindo, Kumamoto, Japan). The GC cells were plated in 96-well plates at 3000 cells/ well and incubated for the indicated times $(0 \mathrm{~h}, 24 \mathrm{~h}, 48$ $\mathrm{h}, 72 \mathrm{~h}$ ), and $10 \mu \mathrm{L}$ CCK- 8 reagent was added directly to the culture medium. The cells were incubated at $37^{\circ} \mathrm{C}$ for $2 \mathrm{~h}$, and the optical density (OD) value was measured at $450 \mathrm{~nm}$ using a microplate reader (BioTeke Corporation, Wuxi, Jiangsu, China).

\section{Colony formation assay}

The cells were plated into a 6-well plate at a density of 1000 cells per well and then incubated for 2 weeks at $37{ }^{\circ} \mathrm{C}$ in $5 \% \mathrm{CO}_{2}$. Then, the cells were fixed with $4 \%$ paraformaldehyde for $20 \mathrm{~min}$ and stained with $0.5 \%$ crystal violet solution for $20 \mathrm{~min}$. The colonies were then counted and analyzed.

\section{TUNEL assay}

$\mathrm{YF}^{\oplus} 488$ TUNEL Assay Apoptosis Detection Kits (Yuhengbio, Suzhou, Jiangsu, China) were used to evaluate the apoptosis rate of GC cells. In brief, the cells were fixed with $4 \%$ paraformaldehyde solution $(\mathrm{pH}=7.4)$ for $30 \mathrm{~min}$ and then treated with $0.2 \%$ TritonX-100 for 20 min for permeabilization. After incubation with $100 \mu \mathrm{L}$ TUNEL equilibration buffer per well for $5 \mathrm{~min}$, the cells were reacted with $50 \mu \mathrm{L}$ TUNEL reaction mixture for 60 min under light-proof conditions. Nuclei were stained for ten minutes using $2 \mu \mathrm{g} / \mathrm{mL}$ 4',6-diamidino-2-phenylindole (DAPI) solution. The cells were then viewed by a fluorescence microscope, and the apoptotic cells were labeled with bright green fluorescence. Apoptosis rate was calculated as the ratio of TUNEL-positive cells to the total number of DAPI-positive cells in five randomly selected regions. 


\section{Wound healing assay}

Wound healing assays were performed to determine the migratory capacity of the cells. The GC cells were plated in 6-well plates at $1 \times 10^{4}$ cells and allowed to grow to 80-90\% confluence. Then, a thin wound was created using a sterile pipette tip $(200 \mu \mathrm{L})$. The gap between the wound edges was imaged at the time points of 0 and 48 h. Wound healing rate (\%) was evaluated by comparing the difference in the wound width by Image software.

\section{Transwell assay}

Cell invasion was assessed using 24-well chambers $(8.0 \mu \mathrm{m}$, Corning Glass Works, Corning, N.Y., USA) precoated with Matrigel (BD Biosciences, San Jose, CA, USA). The GC cells $\left(1 \times 10^{5}\right)$ dispersed in $200 \mu \mathrm{L}$ serumfree medium were placed into the apical chamber, and $600 \mu \mathrm{L}$ medium containing 10\% FBS was added in the basolateral chamber. The cells invaded into the basolateral chamber were fixed with $4 \%$ paraformaldehyde after $24 \mathrm{~h}$ and then treated with $0.5 \%$ crystal violet solution. Observations were made under a microscope, and five fields of view were randomly selected to count the number of invaded cells.

\section{Luciferase reporter assay}

A luciferase reporter assay was used to investigate the effect of MYH11 on the transcriptional activity of the TNFRSF14 promoter. The potential binding sites between MYH11 and the TNFRSF14 promoter were obtained from hTFtarget (http://bioinfo.life.hust.edu.cn/ hTFtarget/\#!/). The TNFRSF14 promoter sequence containing the binding site was inserted into the pGL3-basic vector (Promega Corporation, Madison, WI, USA) to construct a luciferase reporter vector. The above vector plasmids were co-transfected with oe-NC or oe-MYH11 into $293 \mathrm{~T}$ cells (ATCC) using Lipofectamine 2000, respectively. After $48 \mathrm{~h}$ of transfection, luciferase assays were performed using the Dual Luciferase Reporter Gene Assay System kit (Promega).

\section{Chromatin immunoprecipitation (ChIP)}

Protein-DNA interaction was detected using the Pierce ${ }^{\mathrm{Tm}}$ Agarose ChIP Kit (Thermo Fisher Scientific). Briefly, the cells are cross-linked using formaldehyde solution, and chromatin was sheared by enzymatic digestion with micrococcal nuclease (Thermo Fisher). The chromatin was incubated overnight at $4{ }^{\circ} \mathrm{C}$ with antibodies to MYH11, DNMT3A, DNMT3B and $20 \mu \mathrm{L}$ protein A/G plus agarose at $4{ }^{\circ} \mathrm{C}$, with antibody to IgG as a control. All antibodies were supplied by Thermo Fisher. After immunoprecipitation elution and DNA recovery, the purified DNA was subjected to qPCR.

\section{Animal experiments}

This study was approved by the Animal Care and Ethics Committee of the First People's Hospital of Yancheng and carried out in compliance with the Animals in Research: Reporting In vivo Experiments (ARRIVE) guidelines. All animal procedures were in accordance with the Guide for the Care and Use of Laboratory animals published by the US National Institutes of Health. Eight 4week-old male BALB/c nude mice were from Beijing Vital River Laboratory Animal Technology Co., Ltd. (Beijing, China). MKN-7 cells $\left(1 \times 10^{7}\right)$ stably transfected with oe-NC or oe-MYH11 were injected subcutaneously into the right ventral side of nude mice, 4 nude mice per group. The tumor volume was measured weekly with calipers. Tumor volume was calculated as (length $\times$ width $\left.^{2}\right) / 2$. Finally, the mice were euthanized, and the weight of the tumor tissues was examined. The gene expression in tumor tissues was detected by immunohistochemical staining.

\section{Statistical analysis}

All values are expressed as the mean \pm SD. Each assay was performed at least three times. Statistical significance was analyzed by $t$ tests and one-way or two-way ANOVA and Tukey's multiple range tests. The threshold of significance was selected as a $p$ value $<0.05$. Fisher's exact test was used to test for the clinicopathologic parameters of the patients, and log-rank test was used to analyze the survival rate of the patients. Quantitative data analysis was performed in Graph Pad Prism 8.0 (GraphPad Software, Inc., La Jolla, CA, USA).

\section{Results}

\section{Downregulation of MYH11 in GC is associated with poor} prognosis of patients

We performed a pan-cancer analysis in SangerBox (http://sangerbox.com/Tool) and observed a significant downregulation of MYH11 in most cancers, such as GC (Fig. 1A). We then detected the expression of MYH11 in the tumor tissues of $\mathrm{GC}$ patients and their adjacent normal tissues by IHC (Fig. 1B). We found that IHC scores of MYH11 were significantly lower in tumor tissues than that in adjacent tissues. The downregulation of MYH11 in tumor tissues was further substantiated by RT-qPCR assay (Fig. 1C). The patients were divided into MYH11 mRNA high expression group $(n=20)$ and MYH11 mRNA low expression group $(n=20)$ according to the median value of MYH11 mRNA expression in tumor tissues. We then divided the patients into MYH11 high IHC score group $(n=20)$ and MYH11 low IHC score group $(n=20)$ based on the median MYH11 IHC score in the tumor tissues. The five-year survival rate of patients with high MYH11 expression was significantly higher than that of patients with low MYH11 expression 

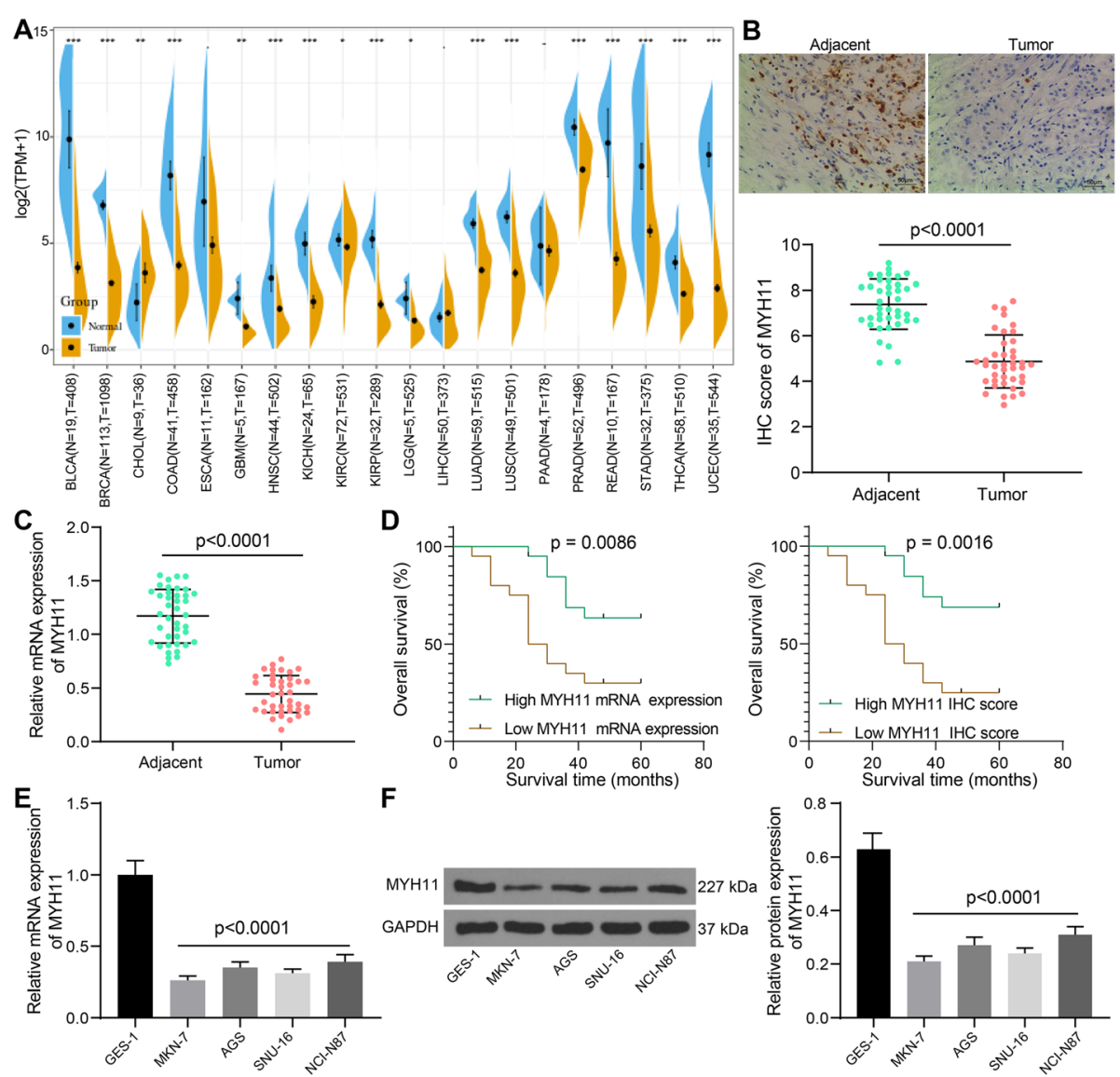

Fig. 1 MYH11 expresses poorly in GC and acts as an indicator for good prognosis. A, MYH11 expression in cancers examined by the SangerBox (http://sangerbox.com/Tool); B, immunohistochemical detection of MYH11 expression in the collected tumor tissues and their adjacent tissues; $\mathbf{C}$, MYH11 expression in collected tumor tissues and their adjacent tissues by RT-qPCR; $\mathbf{D}$, relationship between MYH11 expression in tumor tissues and five-year survival rate of patients examined by Log-rank test; E, MYH11 expression in gastric mucosal epithelial cell line and GC cells by RTqPCR; F, MYH11 expression in gastric mucosal epithelial cell line and GC cells by western blot. Each assay was performed at least three times. Statistical significance was analyzed by $t$ tests (panels B and C) and one-way ANOVA (panels E and F) and Tukey's multiple range tests

(Fig. 1D). By analyzing the clinicopathologic parameters of the patients, we observed that the poor expression of MYH11 also correlated with the tumor size, TNM stage, and lymph node metastasis of the patients (Table 3).

In in vitro experiments, we detected the expression of MYH11 in GES-1 and GC cell lines MKN-7, AGS, SNU16, and NCI-N87 by RT-qPCR and western blot (Fig. 1E, F). The expression of MYH11 was generally reduced in GC cell lines, and MKN-7 and SNU-16 cells with the most significantly reduced MYH11 expression were selected for subsequent cell experiments.

\section{Overexpression of MYH11 inhibits proliferation,} migration, invasion of GC cells, and promotes apoptosis To investigate the effect of abnormally reduced MYH11 on GC cell function, we transfected the overexpression plasmid oe-MYH11 and its control oe-NC into GC cells, and effective transfection was measured by RT-qPCR (Fig. 2A). Overexpression of MYH11 significantly inhibited the growth of GC cells by the CCK8 assay (Fig. 2B). The colony formation assay demonstrated the inhibitory ability of MYH11 on GC cell colony formation (Fig. 2C). We also observed a significant increase in the apoptosis rate of $\mathrm{GC}$ cells after overexpression of MYH11 by TUNEL assay (Fig. 2D). Wound healing assay and Transwell assay were used to detect changes in the migration and invasion of cells (Fig. 2E, F). Overexpression of MYH11 significantly repressed the aggressiveness of GC cells.

\section{MYH11 correlates to TNFRSF14 expression in GC}

To investigate the mechanism by which MYH11 plays a tumor repressive role in $\mathrm{GC}$, we investigated the genes with correlation with MYH11 expression in TCGA database by SangerBox. Three genes, including TNFRSF14, NRP1, and LGALS9 were correlated with MYH11 expression in GC (Fig. 3A). Subsequently, we predicted through hTFtarget that MYH11 has a potential targeting 
Table 3 Relationship between clinicopathologic parameters and the expression of MYH11 in GC

\begin{tabular}{|c|c|c|c|c|c|c|c|c|}
\hline \multirow[t]{2}{*}{ Parameters } & & \multirow{2}{*}{$\begin{array}{l}\text { Total cases } \\
(n=40)\end{array}$} & \multicolumn{2}{|c|}{ MYH11 mRNA expression } & \multirow[t]{2}{*}{$p$ value } & \multicolumn{2}{|c|}{ MYH11 IHC score } & \multirow[t]{2}{*}{$p$ value } \\
\hline & & & High $(n=20)$ & Low $(n=20)$ & & High $(n=20)$ & Low $(n=20)$ & \\
\hline \multirow[t]{2}{*}{ Sex } & Male & 26 & 12 & 14 & 0.7411 & 11 & 15 & 0.3203 \\
\hline & Female & 14 & 8 & 6 & & 9 & 5 & \\
\hline Age & $\geqq 60$ & 21 & 12 & 9 & 0.5273 & 13 & 8 & 0.2049 \\
\hline (year) & $<60$ & 19 & 8 & 11 & & 7 & 12 & \\
\hline Tumor size & $\geqq 3$ & 25 & 9 & 16 & ${ }^{*} 0.0484$ & 7 & 18 & $* * * 0.0008$ \\
\hline$(\mathrm{cm})$ & $<3$ & 15 & 11 & 4 & & 13 & 2 & \\
\hline \multirow[t]{2}{*}{ TNM stage } & $\mid+\|$ & 17 & 13 & 4 & $* * 0.0095$ & 14 & 3 & ${ }^{* *} 0.0011$ \\
\hline & $I I I+I V$ & 23 & 7 & 16 & & 6 & 17 & \\
\hline \multirow[t]{2}{*}{ Tumor site } & Upper GC & 22 & 13 & 9 & 0.3406 & 10 & 12 & 0.7512 \\
\hline & Distal end GC & 18 & 7 & 11 & & 10 & 8 & \\
\hline \multirow[t]{2}{*}{ Lymph node metastasis } & Positive & 25 & 9 & 16 & ${ }^{*} 0.0484$ & 7 & 18 & $* * * 0.0008$ \\
\hline & Negative & 15 & 11 & 4 & & 13 & 2 & \\
\hline
\end{tabular}

Note: Fisher's exact test was used to test for the clinicopathologic parameters of the patients. ${ }^{*} p<0.05,{ }^{* *} p<0.01,{ }^{* * *} p<0.001$. MYH11, myosin heavy chain 11 ; GC, gastric cancer; TNM, tumor, node, metastases; IHC, immunohistochemistry

relationship with TNFRSF14, while no potential targeting relationship with NRP1 and LGALS9 (Fig. 3B).

We first detected the expression of TNFRSF14 in GC tumor tissues and their adjacent tissues by IHC (Fig. 3C). The expression of TNFRSF14 was enhanced in tumor tissues relative to adjacent tissues. The mRNA expression of TNFRSF14 was detected by RT-qPCR, and we observed that its expression was significantly elevated in tumor tissues (Fig. 3D). The expression of TNFRSF14 in tumor tissues was significantly and negatively correlated with the expression of MYH11 (Fig. 3E). The relationship between TNFRSF14 expression and patients' survival was analyzed, and the results showed that the survival rate of patients with low TNFRSF14 expression was significantly higher than that of patients with high expression (Fig. 3F). The high expression of TNFRSF14 was associated with tumor size, TNM stage and lymph node metastasis (Table 4). Meanwhile, the expression of TNFRSF14 was also significantly elevated in GC cells by RT-qPCR and western blot (Fig. 3G, H).

MYH11 transcriptionally represses the expression of TNFR SF14 by binding to its promoter

The effect of overexpression of MYH11 on TNFRSF14 expression in GC cells was examined by RT-qPCR and western blot, and we observed that overexpression of MYH11 significantly inhibited TNFRSF14 expression (Fig. 4A, B). To detect the way MYH11 regulates TNFR SF14 expression, we obtained TNFRSF14 promoter sites from hTFtarget with a potential binding relationship with MYH11 (Fig. 4C). ChIP-qPCR experiments were performed in GC cell lines to detect the enrichment ability of MYH11 for the TNFRSF14 promoter (Fig. 4D). Anti-MYH11 significantly enriched the TNFRSF14 promoter sequence compared to anti-IgG. A luciferase reporter assay was performed to examine the effect of MYH11 on the TNFRSF14 promoter transcriptional activity (Fig. 4E). Overexpression of MYH11 significantly inhibited the promoter transcriptional activity of TNFR SF14.

\section{Overexpression of TNFRSF14 reverses the inhibitory effect of MYH11 on GC cells}

To demonstrate that TNFRSF14 is a downstream functional target of MYH11, we transfected the TNFRSF14 overexpression plasmid oe-TNFRSF14 and the control oe-NC into GC cells overexpressing MYH11. Effective transfection was measured by RT-qPCR (Fig. 5A). CCK8 analysis showed that overexpression of TNFRSF14 significantly enhanced the proliferation of GC cells (Fig. 5B). Also, overexpression of TNFRSF14 promoted the colony formation of GC cells (Fig. 5C). TUNEL assay showed that the apoptosis rate was significantly reduced after overexpression of TNFRSF14 (Fig. 5D). As for changes in the migration and invasion of cells, overexpression of TNFRSF14 significantly reversed the inhibitory effect of MYH11 on the GC cell migration and invasion (Fig. 5E, F).

\section{Elevated methylation level of MYH11 promoter is identified in GC}

Hypermethylation of the promoter region leading to inactivation of oncogenes is one of the common features shared by human tumors. To investigate whether the abnormally reduced expression of MYH11 in GC is associated with hypermethylated modifications in the promoter region, we first obtained the sequence of the CpG island located in the MYH11 promoter from NCBI 


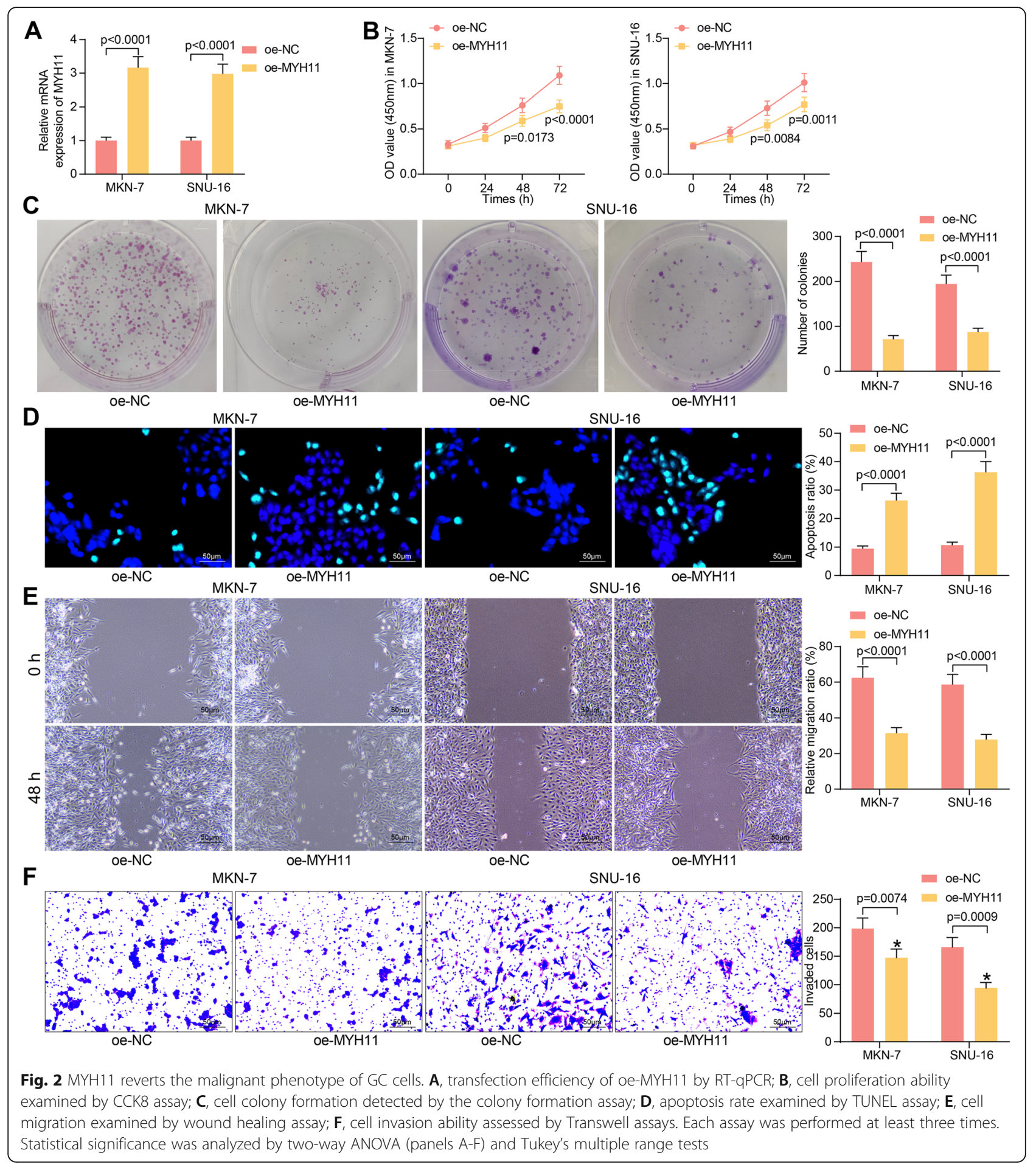

(Fig. 6A). The correctness of the CpG island sequence was confirmed by MethPrimer (Fig. 6B). Subsequently, the methylation level of MYH11 promoter in GC tumor tissues and adjacent tissues was detected by qMSP (Fig. $6 \mathrm{C})$. We observed a significant elevation of MYH11 promoter methylation levels in tumor tissues. Similarly, the methylation level of MYH11 promoter was significantly augmented in GC cells compared to GES-1 cells (Fig. $6 \mathrm{D})$. We treated GC cells with the DNA methylation inhibitor 5-aZa-CDR, which successfully inhibited the methylation of MYH11 promoter in GC cells as detected by qMSP (Fig. 6E). The expression of MYH11 was significantly elevated in GC cells after inhibition of MYH11 promoter methylation by RT-qPCR (Fig. 6F). It was 


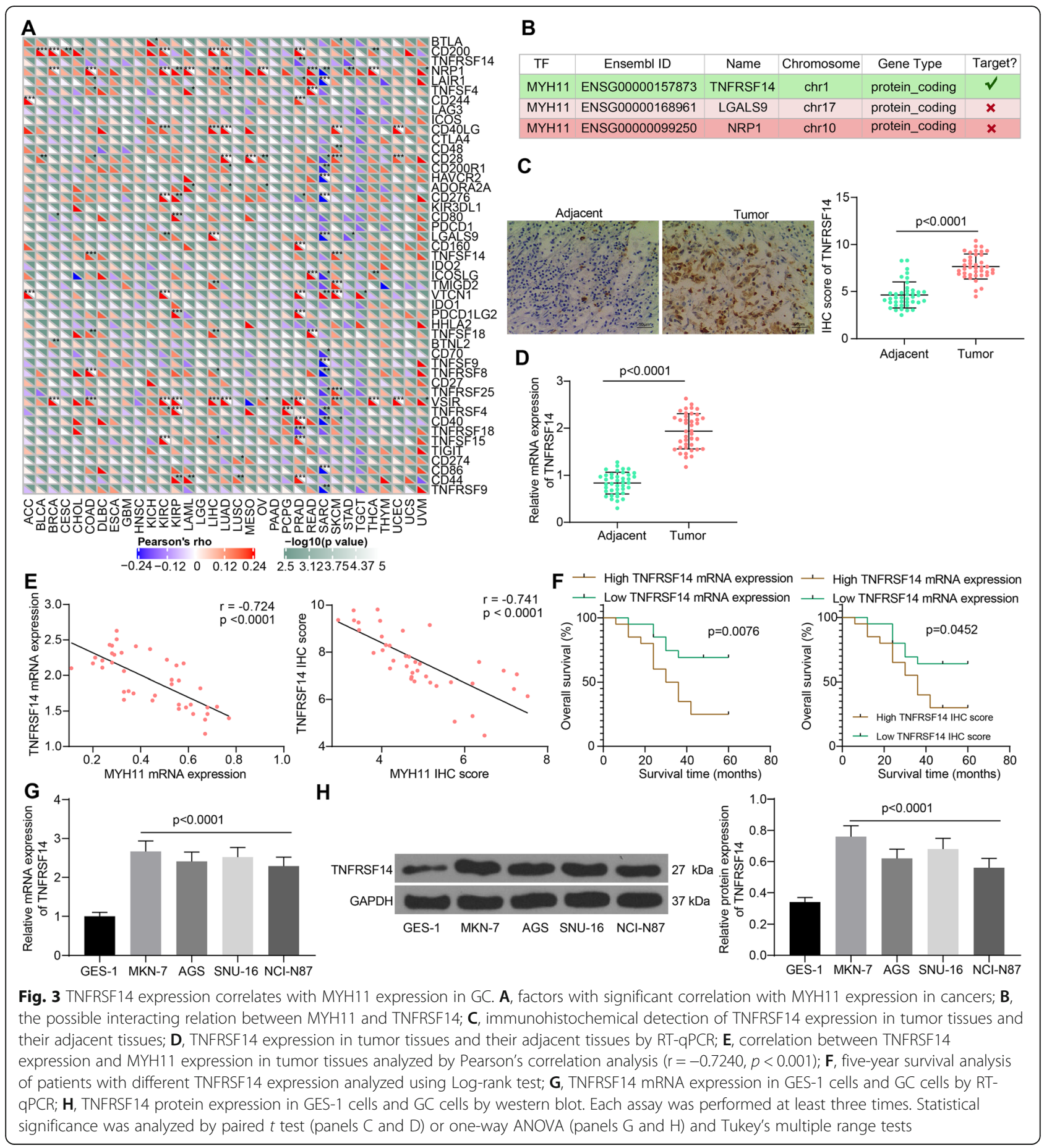

shown that the reduction of MYH11 expression in GC depends on the DNA hypermethylation of its promoter region.

\section{DNMT3B induces DNA hypermethylation of MYH11 promoter}

We queried the expression profile of DNA methyltransferases DNMT3A and DNMT3B, which have been described to be related to CpG island methylation in GC, in the StarBase Pan-cancer platform (http://starbase.sysu.edu.cn/panCancer.php), and we observed that the expression of both was elevated in GC (Fig. 7A). The enrichment ability of DNMT3A and DNMT3B for MYH11 promoter was examined by ChIP-qPCR, and we observed that both could enrich MYH11 promoter sequence, while DNMT3B 
Table 4 Relationship between clinicopathologic parameters and the expression of TNFRSF14 in GC

\begin{tabular}{|c|c|c|c|c|c|c|c|c|}
\hline \multirow[t]{2}{*}{ Parameters } & & \multirow{2}{*}{$\begin{array}{l}\text { Total cases } \\
(n=40)\end{array}$} & \multicolumn{2}{|c|}{ TNFRSF14 mRNA expression } & \multirow[t]{2}{*}{$p$ value } & \multicolumn{2}{|c|}{ TNFRSF14 IHC score } & \multirow[t]{2}{*}{$p$ value } \\
\hline & & & High $(n=20)$ & Low $(n=20)$ & & High $(n=20)$ & Low $(n=20)$ & \\
\hline \multirow[t]{2}{*}{ Sex } & Male & 26 & 16 & 10 & 0.0958 & 13 & 13 & $>0.9999$ \\
\hline & Female & 14 & 4 & 10 & & 7 & 7 & \\
\hline Age & $\geqq 60$ & 21 & 8 & 13 & 0.2049 & 9 & 12 & 0.5273 \\
\hline (year) & $<60$ & 19 & 12 & 7 & & 11 & 8 & \\
\hline Tumor size & $\geqq 3$ & 25 & 17 & 8 & **0.0079 & 16 & 9 & *0.0484 \\
\hline$(\mathrm{cm})$ & $<3$ & 15 & 3 & 12 & & 4 & 11 & \\
\hline \multirow[t]{2}{*}{ TNM stage } & $1+\|$ & 17 & 3 & 14 & ${ }^{* *} 0.0011$ & 2 & 15 & $* * * 0.0004$ \\
\hline & $I I I+I V$ & 23 & 17 & 6 & & 18 & 5 & \\
\hline \multirow[t]{2}{*}{ Tumor site } & Upper GC & 22 & 11 & 11 & $>0.9999$ & 14 & 8 & 0.1110 \\
\hline & Distal end GC & 18 & 9 & 9 & & 6 & 12 & \\
\hline \multirow[t]{2}{*}{ Lymph node metastasis } & Positive & 25 & 17 & 8 & ${ }^{* *} 0.0079$ & 19 & 6 & $* * * 0.0002$ \\
\hline & Negative & 15 & 3 & 12 & & 1 & 14 & \\
\hline
\end{tabular}

Note: Fisher's exact test was used to test for the clinicopathologic parameters of the patients. ${ }^{*} p<0.05,{ }^{* *} p<0.01,{ }^{* * *} p<0.001$. TNFRSF14/HVEM, herpes virus entry mediator; GC, gastric cancer; TNM, tumor, node, metastases; IHC, immunohistochemistry

showed more prominent enrichment ability (Fig. 7B). Therefore, we selected DNMT3B for the following study.

The expression of DNMT3B was detected by RTqPCR in the collected tumor tissues and adjacent tissues, and we found that its expression was significantly elevated in the tumor tissues (Fig. 7C). The expression of DNMT3B in tumor tissues was positively correlated with the methylation of MYH11 promoter (Fig. 7D) and conversely correlated with the expression of MYH11 (Fig. 7E). We transfected DNMT3B overexpression plasmids into GC cells, and effective transfection was obtained by RT-qPCR (Fig. 7F). qMSP assayed the methylation level of MYH11 promoter in cells, and we observed that overexpression of DNMT3B significantly promoted the methylation modification of MYH11 promoter (Fig. 7G). Further RT-qPCR results also showed that

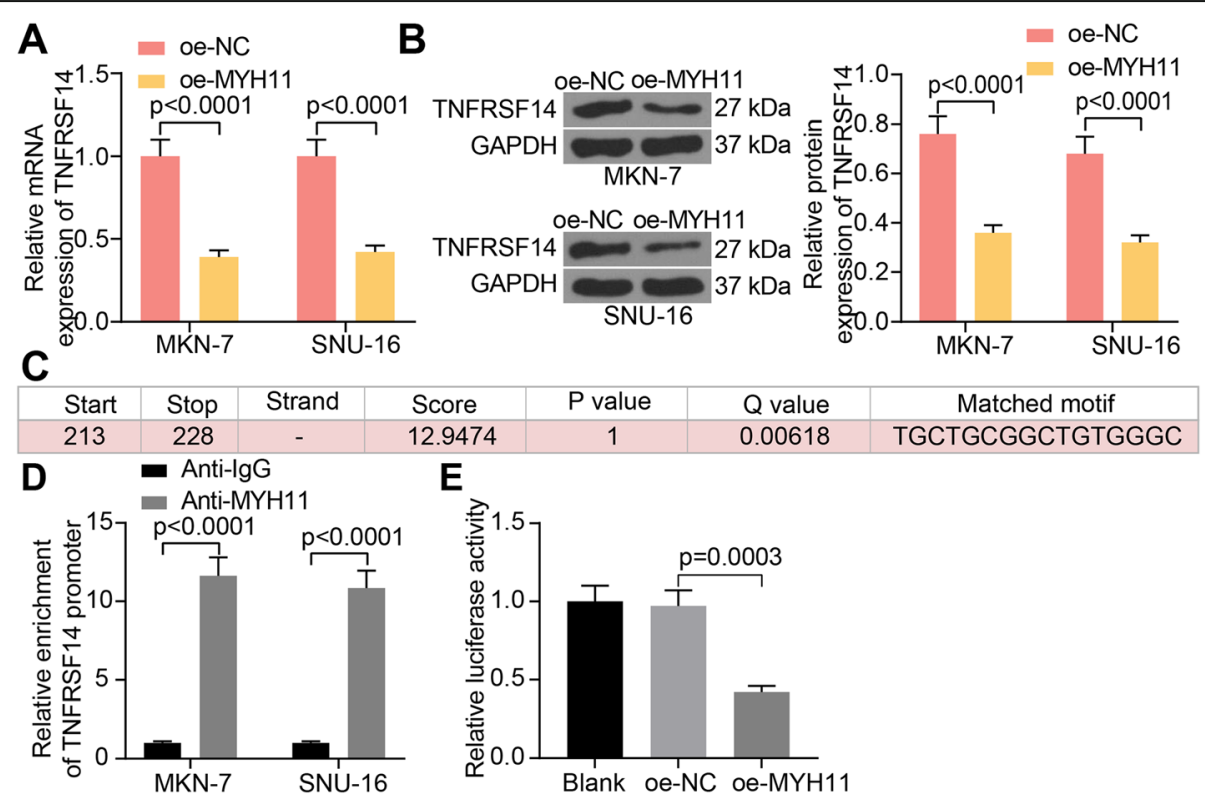

Fig. 4 MYH11 interacts with TNFRSF14 by direct binding in GC cells. A, TNFRSF14 expression in GC cells in response to oe-MYH11 or oe-NC by RT-qPCR; B, TNFRSF14 expression in GC cells in response to oe-MYH11 or oe-NC by western blot; $\mathbf{C}$, the binding sites between MYH11 and TNFR SF14 promoter; D, the enrichment ability of MYH11 on TNFRSF14 promoter examined by ChIP-qPCR; $\mathbf{E}$, the transcriptional activity of TNFRSF14 promoter detected by a luciferase report assay. Each assay was performed at least three times. Statistical significance was analyzed by one-way (panel E) or two-way ANOVA (panels A, B and D) and Tukey's multiple range tests 


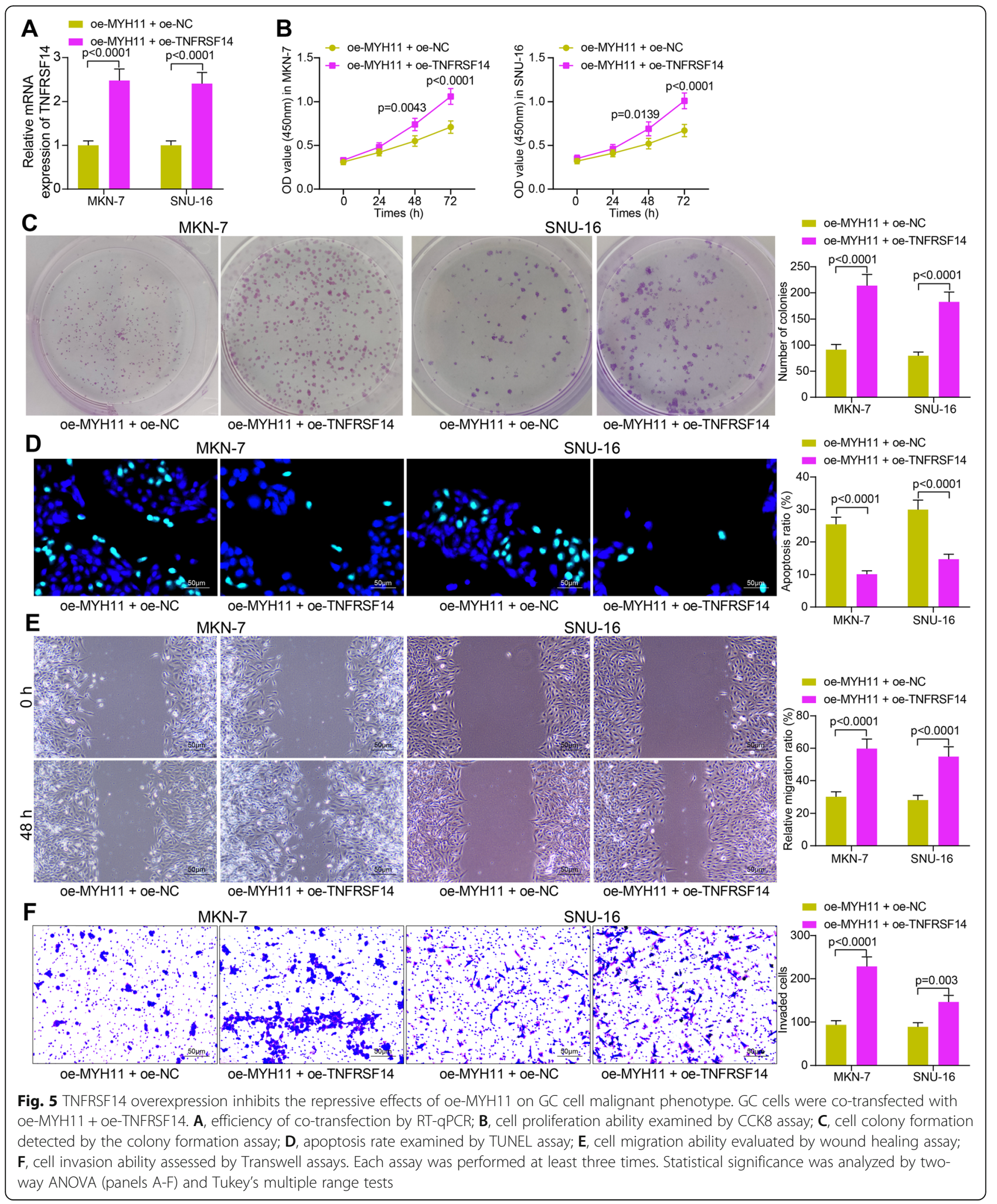

overexpression of DNMT3B suppressed the expression of MYH11 (Fig. 7H). We demonstrated experimentally that MYH11 promoter hypermethylation in GC was caused by the overexpression of DNMT3B.
Overexpression of MYH11 inhibits tumor growth in vivo We injected GC cells overexpressing MYH11 subcutaneously into the ventral side of nude mice to perform tumor xenograft experiments. To reduce unnecessary 


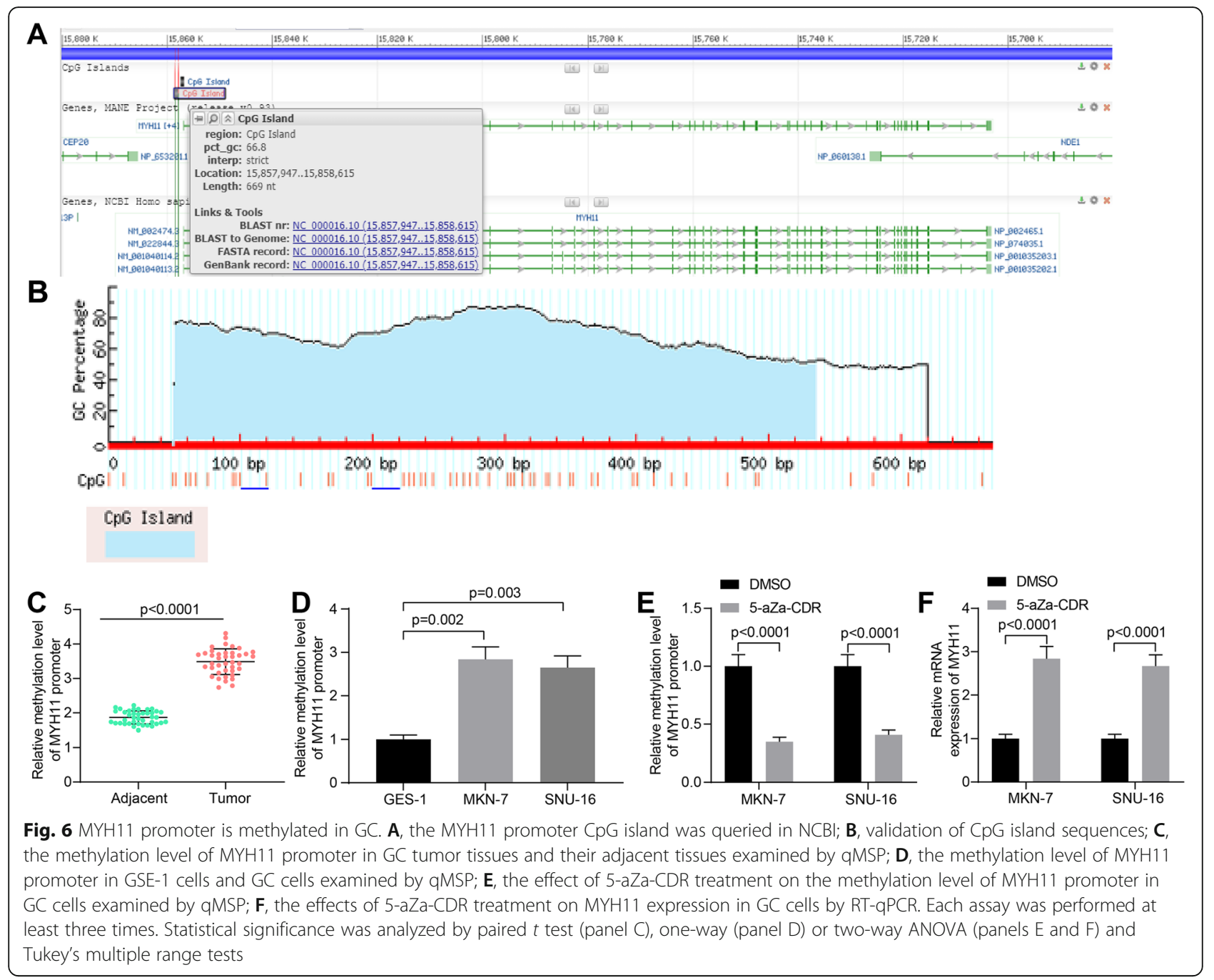

animal sacrifice, we only used MKN-7 cells for in vivo experiments. Tumor volume was measured weekly for 4 weeks starting on the seventh day of injection. We found that tumor growth was significantly slower in the oe-MYH11 group compared to the oeNC group (Fig. 8A). Four weeks later, tumor tissues were harvested and weighed (Fig. 8B). A significant decrease was noted in tumor weight in the MYH11 overexpression group. By immunohistochemical detection of MYH11, TNFRSF14, and Ki67 expression in harvested xenograft tumors, we observed a significant increase in MYH11 expression and a significant decrease in Ki67 and TNFRSF14 expression in tumor tissues from the mice injected with cells overexpressing MYH11 (Fig. 8C).

\section{Discussion}

Carcinogenesis of GC is a multistep process characterized by a broad spectrum of molecular alterations [16]. DNA methylation, the most frequent epigenetic mechanism, is spotted almost entirely in CpG dinucleotides which tend to cluster in areas called CpG islands and exists in approximately $70 \%$ of human gene promoters [17]. In this study, a relationship was substantiated between MYH11 downregulation and the hypermethylation of its promoter in GC, and poorly expressed MYH11 was correlated with a poor prognosis and was intimately intertwined with tumor size, TNM stage, and lymph node metastasis of GC patients. Additionally, as implied by gain-of-function assays, MYH11 overexpression inhibited cell migration, proliferation and invasion. Therefore, our findings unveiled the tumor suppressor role of MYH11 in GC.

Saeki et al. has long established that MYH11 is not expressed in GC cell lines [18]. Furthermore, colorectal cancer patients with lower MYH11 expression inclined to have a dismal prognosis, and poor MYH11 expression evidenced to be an independent adverse prognosticator [19]. These findings were largely in agreement with the observations of our study. Moreover, MYH11, increased 


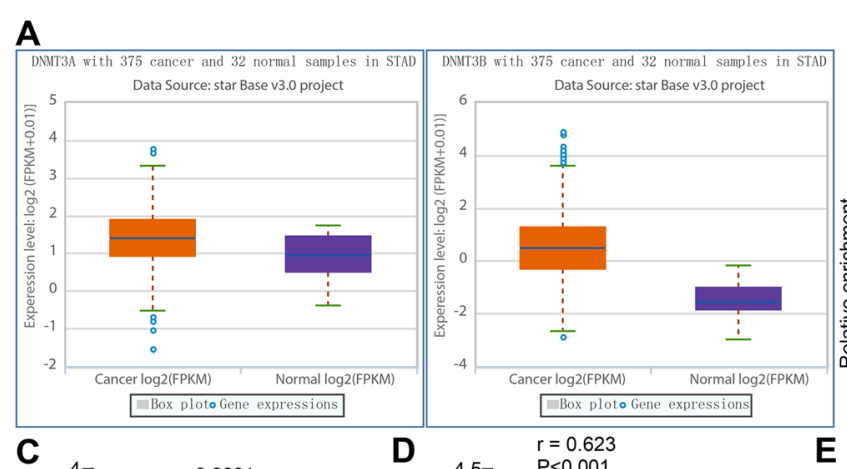

B
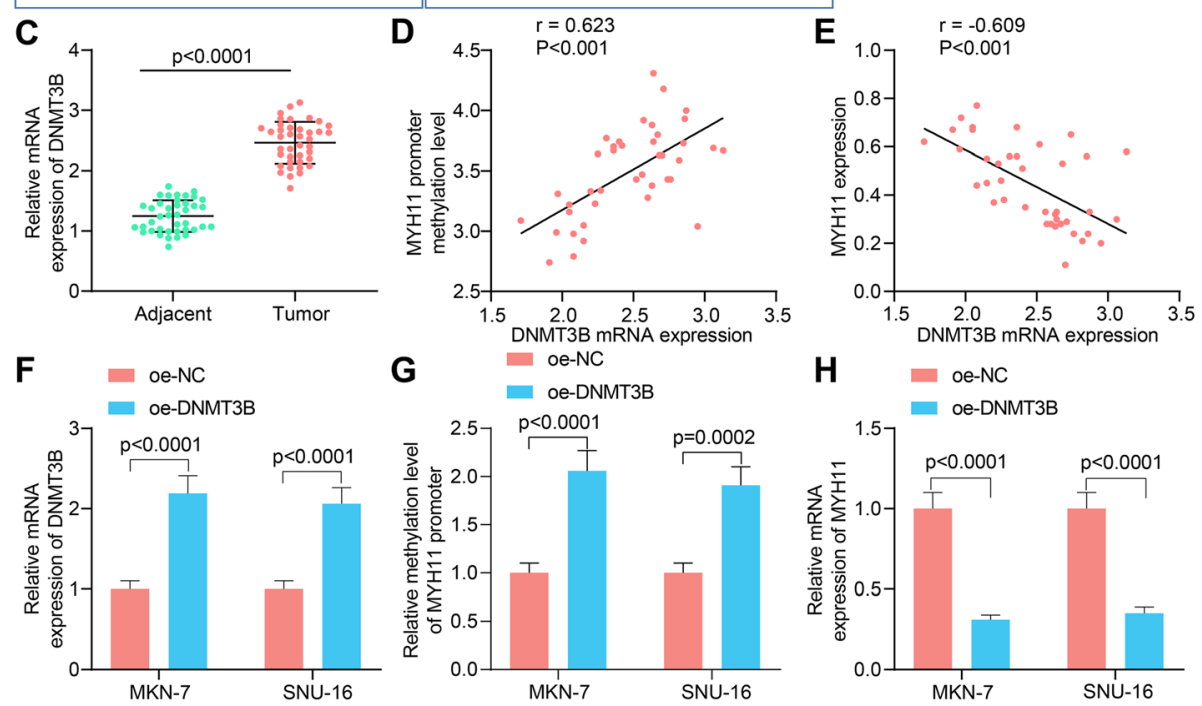

Fig. 7 DNMT3B upregulation is responsible for the hypermethylation of the MYH11 promoter. $\mathbf{A}$, the expression of DNMT3A and DNMT3B in GC was queried in StarBase Pan-cancer platform; B, the enrichment ability of DNMT3A and DNMT3B on MYH11 promoter examined by ChIP-qPCR; C, DNMT3B mRNA expression in GC tumor tissues and their adjacent tissues by RT-qPCR; $\mathbf{D}$, correlation of DNMT3B expression with MYH11

promoter methylation levels in tumor tissues analyzed by Pearson's correlation analysis $(r=0.623, p<0.001)$; $\mathbf{E}$, correlation of DNMT3B expression with MYH11 expression in tumor tissues $(r=-0.609, p<0.001) ; \mathbf{F}$, transfection efficiency of oe-DNMT3B in GC cells by RT-qPCR; $\mathbf{G}$, the effects of DNMT3B overexpression on the methylation level of MYH11 promoter examined by qMSP; $\mathbf{H}$, effects of DNMT3B overexpression on MYH11 expression by RT-qPCR. Each assay was performed at least three times. Statistical significance was analyzed by paired $t$ test (panel C) or two-way ANOVA (panels B, F, G and H) and Tukey's multiple range tests

by treatment of $\mathrm{H}_{2} \mathrm{O}_{2}$, could reduce proliferation and elevate apoptosis of mouse aortic smooth muscle cells [20]. While the functional role of MYH11 is less studied in cancers. Our gain-of-function assays exhibited that MYH11 showed anti-proliferatory, anti-migratory, antiinvasive, while pro-apoptotic properties in GC cells. Furthermore, we utilized bioinformatics websites to screen for the downstream target of MYH11. TNFRSF14 (also termed as HVEM) was revealed as the only result. As we mentioned previously, MYH11 could serve as a transcription factor. Therefore, we downloaded the possible binding sites between MYH11 and TNFRSF14 for connection validation. Subsequent ChIP and luciferase reporter assay attested our hypothesis. TNFRSF14 was significantly promoted in non-small cell lung cancer patients with N2 lymph node metastasis or more advanced stage [21]. Overexpression of TNFRSF14 was associated with poor overall survival and disease-free survival in patients with clear cell renal cell carcinoma, and TNFR SF14 silencing resulted in an evident decline in cell growth both in vitro and in vivo [22]. Similarly, Migita et al. reported that knockdown of TNFRSF14 significantly repressed esophageal squamous cell carcinoma cell proliferation in vitro and growth in vivo [23]. More relevantly, the elevated TNFRSF14 levels correlated with the development and poor prognosis of GC [24]. The rescue experiments carried out in the present study demonstrated that upregulation of TNFRSF14 reversed the inhibitory effects of MYH11 overexpression on GC cell malignant phenotype.

Epigenetic alterations, including DNA methylation, might initiate and support changes that contribute to the inactivation of tumor-suppressor and other cancerassociated genes in GC [25]. Figueroa et al. proposed that established CBFb-MYH11 leukemia entity was highly linked to methylation profiles [26]. Thus, we next 


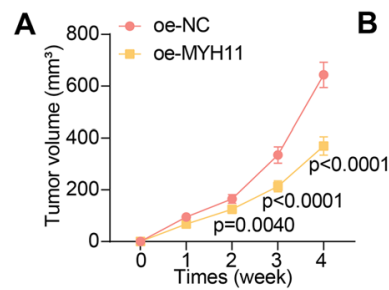

C

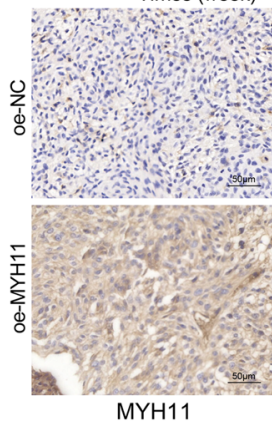

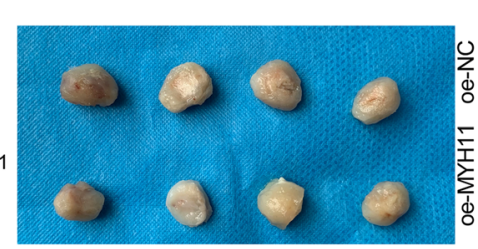
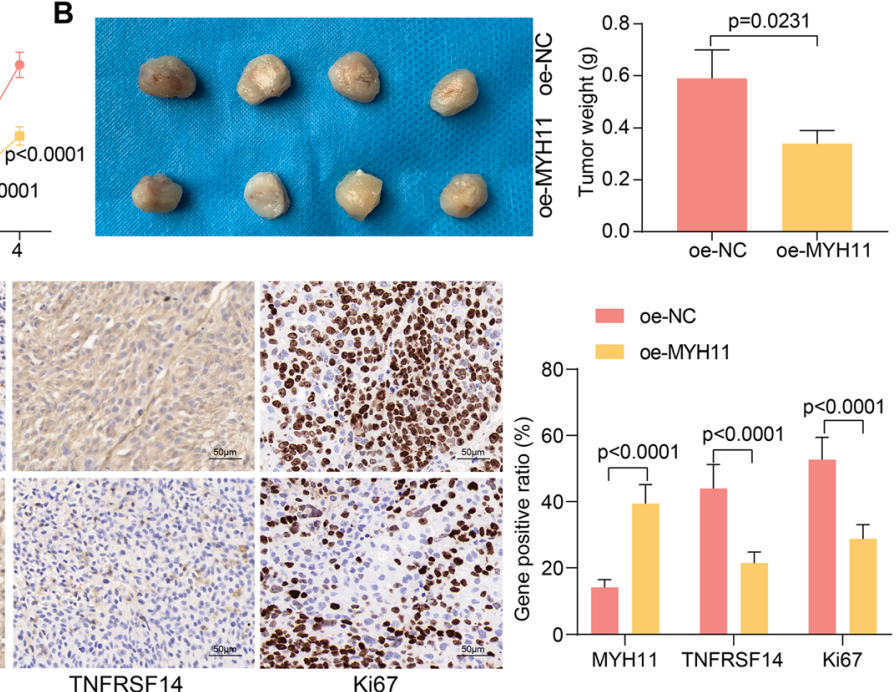

Fig. 8 MYH11 overexpression impedes tumor growth in GC. GC cells transfected with oe-MYH11 or oe-NC were delivered into nude mice ( $n=4)$. A, tumor growth rate; B, weight of harvested xenograft tumors; C, immunohistochemical detection of MYH1 1, TNFRSF14, and Ki67 expression in xenograft tumors. Statistical significance was analyzed by unpaired $t$ test (panel B) or two-way ANOVA (panels A and C) and Tukey's multiple range tests

probed whether the downregulation of MYH11 in GC was induced by the methylation of its promoter as well. qMSP revealed the significant increase in the methylation level of MYH11 promoter in GC tissues and cell lines relative to their counterparts. Additional qMSP and RT-qPCR assays using 5 -aZa-CDR further verified that the high methylation level was responsible for the downregulation of MYH11 in GC. Likewise, MSP implemented by Shahmohamadnejad et al. showed that the hypermethylation of miR-124 promoter region led to its remarkable downregulation in colorectal cancer tissues, and miR-124 expression was restored following 5-aZaCDR treatment [27]. Our ensuing ChIP-qPCR assay determined that DNMT3B, instead of DNMT3A, showed

Promoting GC cells proliferation,migration and invasion, and inhibiting apoptosis

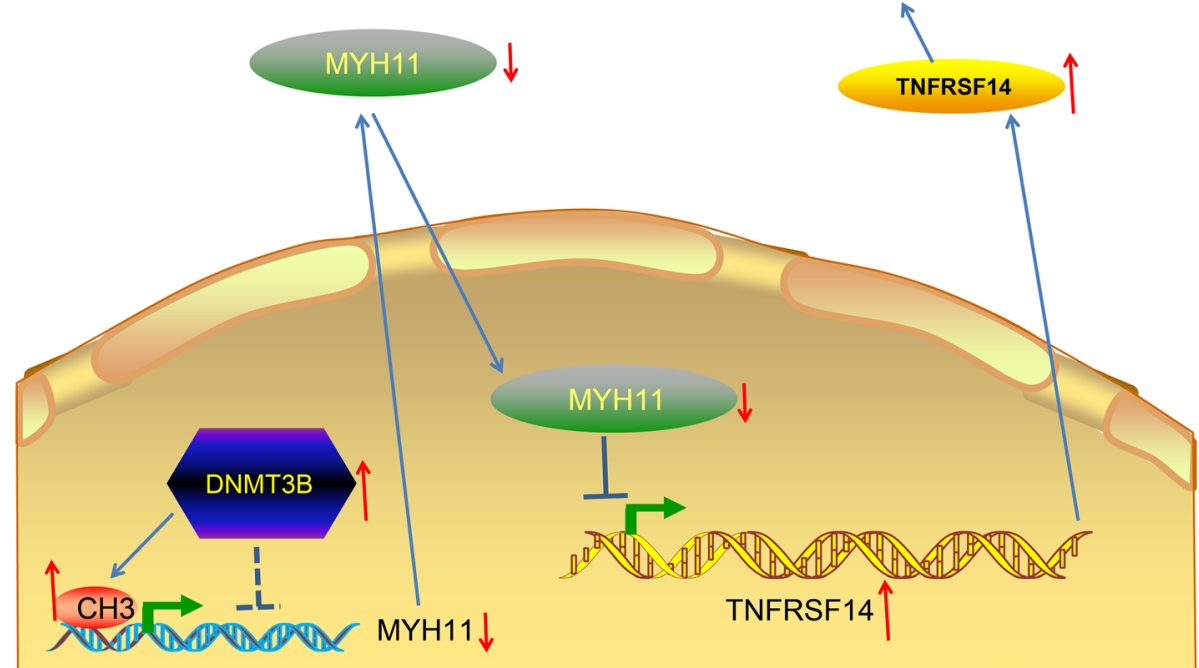

Fig. 9 Mechanism diagram. Overexpression of DNMT3B in GC inhibited MYH11 expression by promoting methylation of the MYH11 promoter, thereby attenuating the repressive effect of MYH11 on TNFRSF14 transcriptional activity and promoting GC progression 
higher enrichment ability for MYH11 promoter sequence. Protein and mRNA expression of DNMT3B were found enhanced in melanoma and GC [28-30]. Also, DNA hypermethylation at the $\mathrm{CpG}$ sites in the promoter of $\mathrm{N}$-myc downstream regulated gene 2 observed in GC was related to upregulated DNMT3B expression caused by H. pylori treatment [31].

\section{Conclusion}

Overall, we discovered in this study that MYH11 expression is markedly decreased in GC tissues and cells, and that the loss of MYH11 expression is correlated with an unsatisfactory prognosis of GC patients. Overexpression of MYH11 increased the apoptosis of GC cells, and reduced the growth and tumorigenicity of GC cells by reducing the expression of TNFRSF14. Furthermore, our results indicated that DNMT3B exerts an inhibitory effect on MYH11 expression by methylation of its promoter (Fig. 9). These results suggested that MYH11 may be a crucial prognostic and therapeutic target for patients with GC, providing a new direct for future research.

\section{Abbreviations}

CCK-8: cell counting kit-8; ChIP: chromatin immunoprecipitation; DAPI: 4,'6diamidino-2-phenylindole; DNMT3B: DNA methyltransferase 3b; FBS: fetal bovine serum; GAPDH: glyceraldehyde-3-phosphate dehydrogenase; GC: gastric cancer; MSP: Methylation specific PCR; MYH11: myosin heavy chain 11; NC: negative control; OD: optical density; TNFRSF14/HVEM: herpes virus entry mediator; TUNEL: Terminal deoxynucleotidyl transferase (TdT)mediated 2'-Deoxyuridine 5'-Triphosphate (dUTP) nick end labeling

\section{Supplementary Information}

The online version contains supplementary material available at https:/doi. org/10.1186/s12885-021-08653-3.

\section{Additional file 1}

\section{Acknowledgments}

Not applicable.

\section{Authors' contributions}

Jianhua Wang and Ping Xu: Conceptualization, Methodology, Experimental studies, Software; Yanping Hao and Tingting Yu: Data curation, Statistical analysis, Experimental studies; Limin Liu and Yan Song: Visualization, Experimental studies, statistical analysis; Yan Li: Manuscript preparation, Reviewing and Editing, Validation; All authors read and approved the final manuscript.

\section{Funding}

Not applicable.

\section{Availability of data and materials}

All the data generated or analyzed during this study are included in this published article.

\section{Declarations}

\section{Ethics approval and consent to participate}

The study protocol was approved by the Ethics Committee of the First People's Hospital of Yanchengand and conducted according to the Declaration of Helsinki. Written informed consent was acquired from all of the patients. This study was approved by the Animal Care and Ethics Committee of the First People's Hospital of Yancheng and carried out in compliance with the Animals in Research: Reporting In vivo Experiments (ARRIVE) guidelines. All animal procedures were in accordance with the Guide for the Care and Use of Laboratory animals published by the US National Institutes of Health.

\section{Consent for publication}

Not applicable.

\section{Competing interests}

The authors declare that they have no conflict of interest.

\section{Author details}

'Department of Gastroenterology, The Yancheng Clinical College of Xuzhou Medical University, The First People's Hospital of Yancheng, Yancheng 224001, Jiangsu, People's Republic of China. ${ }^{2}$ Department of Obstetrics and Gynecology, The Yancheng Clinical College of Xuzhou Medical University, The First People's Hospital of Yancheng, No. 66, Renmin South Road, Yancheng 224001, Jiangsu, People's Republic of China.

Received: 17 May 2021 Accepted: 5 August 2021

Published online: 12 August 2021

\section{References}

1. Siegel RL, Miller KD, Fuchs HE, Jemal A. Cancer statistics, 2021. CA Cancer J Clin. 2021;71(1):7-33. https://doi.org/10.3322/caac.21654.

2. Bray F, Ferlay J, Soerjomataram I, Siegel RL, Torre LA, Jemal A. Global cancer statistics 2018: GLOBOCAN estimates of incidence and mortality worldwide for 36 cancers in 185 countries. CA Cancer J Clin. 2018;68(6):394-424. https://doi.org/10.3322/caac.21492.

3. Karimi P, Islami F, Anandasabapathy S, Freedman ND, Kamangar F. Gastric cancer: descriptive epidemiology, risk factors, screening, and prevention. Cancer Epidemiol Biomark Prev. 2014;23(5):700-13. https://doi.org/10.1158/1 055-9965.EPI-13-1057.

4. Pasechnikov V, Chukov S, Fedorov E, Kikuste I, Leja M. Gastric cancer: prevention, screening and early diagnosis. World J Gastroenterol. 2014; 20(38):13842-62. https://doi.org/10.3748/wjg.v20.i38.13842.

5. Digklia A, Wagner AD. Advanced gastric cancer: current treatment landscape and future perspectives. World J Gastroenterol. 2016;22(8):240314. https://doi.org/10.3748/wjg.v22.i8.2403.

6. Nie MJ, Pan XT, Tao HY, Xu MJ, Liu SL, Sun W, et al. Clinical and prognostic significance of MYH11 in lung cancer. Oncol Lett. 2020;19(6):3899-906. https://doi.org/10.3892/ol.2020.11478.

7. Douet-Guilbert N, Chauveau A, Gueganic N, Guillerm G, Tous C, Le Bris MJ, et al. Acute myeloid leukaemia (FAB AML-M4Eo) with cryptic insertion of cbfb resulting in cbfb-Myh11 fusion. Hematol Oncol. 2017;35(3):385-9. https://doi.org/10.1002/hon.2268.

8. Islam T, Rahman R, Gov E, Turanli B, Gulfidan G, Haque A, et al. Drug targeting and biomarkers in head and neck cancers: insights from systems biology analyses. OMICS. 2018;22(6):422-36. https://doi.org/10.1089/omi.201 8.0048.

9. Ma Q, Xu Y, Liao H, Cai Y, Xu L, Xiao D, et al. Identification and validation of key genes associated with non-small-cell lung cancer. J Cell Physiol. 2019; 234(12):22742-52. https://doi.org/10.1002/jcp.28839.

10. Hu J, Zhou L, Song Z, Xiong M, Zhang Y, Yang Y, et al. The identification of new biomarkers for bladder cancer: a study based on TCGA and GEO datasets. J Cell Physiol. 2019;234(9):15607-18. https://doi.org/10.1002/jcp.282 08.

11. Xi WD, Liu YJ, Sun XB, Shan J, Yi L, Zhang TT. Bioinformatics analysis of RNAseq data revealed critical genes in colon adenocarcinoma. Eur Rev Med Pharmacol Sci. 2017;21(13):3012-20.

12. Jo YS, Kim MS, Yoo NJ, Lee SH. Somatic mutations and Intratumoral heterogeneity of MYH11 gene in gastric and colorectal cancers. Appl Immunohistochem Mol Morphol. 2018;26(8):562-6. https://doi.org/10.1097/ PAl.00000000000000484.

13. Sun YL, Zhang Y, Guo YC, Yang ZH, Xu YC. A prognostic model based on six metabolism-related genes in colorectal Cancer. Biomed Res Int. 2020 2020:5974350. 
14. Wu J, Gu Y, Xiao Y, Xia C, Li H, Kang Y, et al. Characterization of DNA methylation associated gene regulatory networks during stomach Cancer progression. Front Genet. 2018;9:711.

15. Zhong JY, Cui RR, Lin X, Xu F, Zhu T, Li F, et al. Aberrant DNA methylation of synaptophysin is involved in adrenal cortisol-producing adenoma. Aging (Albany NY). 2019;11(14):5232-45. https://doi.org/10.18632/aging.102119.

16. Yasui W, Sentani K, Sakamoto N, Anami K, Naito Y, Oue N. Molecular pathology of gastric cancer: research and practice. Pathol Res Pract. 2011; 207(10):608-12. https://doi.org/10.1016/j.prp.2011.09.006.

17. Gigek CO, Chen ES, Calcagno DQ, Wisnieski F, Burbano RR, Smith MA. Epigenetic mechanisms in gastric cancer. Epigenomics. 2012;4(3):279-94. https://doi.org/10.2217/epi.12.22.

18. Saeki N, Komatsuzaki R, Chiwaki F, Yanagihara K, Sasaki H. A GSDMB enhancer-driven HSV thymidine kinase-expressing vector for controlling occult peritoneal dissemination of gastric cancer cells. BMC Cancer. 2015; 15(1):439. https://doi.org/10.1186/s12885-015-1436-1.

19. Wang RJ, Wu P, Cai GX, Wang ZM, Xu Y, Peng JJ, et al. Down-regulated MYH11 expression correlates with poor prognosis in stage II and III colorectal cancer. Asian Pac J Cancer Prev. 2014;15(17):7223-8. https://doi. org/10.7314/APJCP.2014.15.17.7223.

20. Xiao W, Li X, Ji C, Shi J, Pan Y. LncRNA Sox2ot modulates the progression of thoracic aortic aneurysm by regulating miR-330-5p/Myh11. Biosci Rep. 2020; 40(7)

21. Ren S, Tian Q, Amar N, Yu H, Rivard CJ, Caldwell C, et al. The immune checkpoint, HVEM may contribute to immune escape in non-small cell lung cancer lacking PD-L1 expression. Lung Cancer. 2018;125:115-20. https://doi. org/10.1016/j.lungcan.2018.09.004

22. Tang M, Cao X, Li Y, Li GQ, He QH, Li SJ, et al. High expression of herpes virus entry mediator is associated with poor prognosis in clear cell renal cell carcinoma. Am J Cancer Res. 2019:9(5):975-87.

23. Migita K, Sho M, Shimada K, Yasuda S, Yamato I, Takayama T, et al. Significant involvement of herpesvirus entry mediator in human esophageal squamous cell carcinoma. Cancer. 2014;120(6):808-17. https://doi.org/10.1 002/cncr.28491.

24. Lan X, Li S, Gao H, Nanding A, Quan L, Yang C, et al. Increased BTLA and HVEM in gastric cancer are associated with progression and poor prognosis. Onco Targets Ther. 2017:10:919-26. https://doi.org/10.2147/OTT.S128825.

25. Fattahi S, Golpour M, Amjadi-Moheb F, Sharifi-Pasandi M, Khodadadi P Pilehchian-Langroudi $\mathrm{M}$, et al. DNA methyltransferases and gastric cancer: insight into targeted therapy. Epigenomics. 2018;10(11):1477-97. https://doi. org/10.2217/epi-2018-0096.

26. Figueroa ME, Lugthart S, Li Y, Erpelinck-Verschueren C, Deng X, Christos PJ et al. DNA methylation signatures identify biologically distinct subtypes in acute myeloid leukemia. Cancer Cell. 2010;17(1):13-27. https://doi.org/10.101 6/j.ccr.2009.11.020

27. Shahmohamadnejad S, Nouri Ghonbalani Z, Tahbazlahafi B, Panahi G, Meshkani R, Emami Razavi A, et al. Aberrant methylation of miR-124 upregulates DNMT3B in colorectal cancer to accelerate invasion and migration. Arch Physiol Biochem. 2020:1-7. https://doi.org/10.1080/138134 55.2020 .1779311

28. Li Y, Yan J, Wang Y, Wang C, Zhang C, Li G. LINC00240 promotes gastric cancer cell proliferation, migration and EMT via the miR-124-3p / DNMT3B axis. Cell Biochem Funct. 2020;38(8):1079-88. https://doi.org/10.1002/cbf.3 551.

29. Micevic G, Theodosakis N, Bosenberg M. Aberrant DNA methylation in melanoma: biomarker and therapeutic opportunities. Clin Epigenetics. 2017; 9(1):34. https://doi.org/10.1186/s13148-017-0332-8.

30. Wu S, Xie J, Shi H, Wang ZW. miR-492 promotes chemoresistance to CDDP and metastasis by targeting inhibiting DNMT3B and induces stemness in gastric cancer. Biosci Rep. 2020;40(3).

31. Ling ZQ, Ge MH, Lu XX, Han J, Wu YC, Liu X, et al. Ndrg2 promoter hypermethylation triggered by helicobacter pylori infection correlates with poor patients survival in human gastric carcinoma. Oncotarget. 2015;6(10): 8210-25. https://doi.org/10.18632/oncotarget.3601.

\section{Publisher's Note}

Springer Nature remains neutral with regard to jurisdictional claims in published maps and institutional affiliations.

Ready to submit your research? Choose BMC and benefit from:

- fast, convenient online submission

- thorough peer review by experienced researchers in your field

- rapid publication on acceptance

- support for research data, including large and complex data types

- gold Open Access which fosters wider collaboration and increased citations

- maximum visibility for your research: over $100 \mathrm{M}$ website views per year

At $\mathrm{BMC}$, research is always in progress.

Learn more biomedcentral.com/submissions 